\title{
Parent satisfaction with a pediatric practice in Germany: A questionnaire-based study
}

\author{
Anne Weissenstein ${ }^{\dagger}$, Alexandra Straeter ${ }^{\dagger}$, Gloria Villalon $^{\dagger}$, Elisabeth Luchter $^{\dagger}$ and Stefan Bittmann $^{* \dagger}$
}

\begin{abstract}
Background: Parental satisfaction with a pediatric day center is essential for the medical treatment of children, since it is closely related to compliance. In order to ascertain factors which predict parental satisfaction as well as to discover possible weak points, we developed a questionnaire.

Methods: 127 parents visiting the pediatric day center from October to November 2010 were asked to respond to a questionnaire. The survey was given to them directly by the doctor after their visit and it provided the opportunity to determine subjective and soft factors in quality management, which is essential for a pediatric practice. The questionnaire consisted of 27 items divided into three scales. The scales were as follows: satisfaction concerning the infrastructure and organization, satisfaction concerning the communicative and empathic competence of the doctor as well as the other staff, and finally the results and the overall impression. Moreover, the survey asked the respondents for their comments on the pediatric day center and sociodemographic data were queried.

Results: A total of 67 parents (52,7\%) responded to the survey. The mean parental satisfaction concerning infrastructure and organization achieved 3,61 (scale 1-very unsatisfied-through 4-very satisfied). The mean satisfaction with the expertise of the doctor and the staff was 3,56 and the overall satisfaction was 3,65. Ninety-one percent of the parents would visit the pediatric practice again and $84,2 \%$ would definitely recommend the practice to others.

Conclusion: Surveys on parental satisfaction are essential for the success of a pediatric day center. Apart from the doctors abilities to interact with the parents, other factors, such as a short waiting period, a friendly and helpful staff, as well as appealing premises are essential for a high overall level of satisfaction.
\end{abstract}

Keywords: parent satisfaction, pediatrics, pediatric practice

\section{Background}

Patient satisfaction, or parent satisfaction in the case of children under medical care, is a construct from social research, which describes the satisfaction of patients with demanded services from the health care system. The National Center for Health services Research and health care Technology Assessment has identified patient satisfaction as one of the three major categories of criteria for the evaluation of health care systems [1]. Specifically the term "patient satisfaction" is described by the discrepancy between the quality of the medical

\footnotetext{
* Correspondence: bittmann@ped-mind-institute.de

† Contributed equally

Ped Mind Institute, Aerzte- und Finanzzentrum Epe, Hindenburgring 4, 48599 Gronau, Germany
}

\section{() Biomed Central}

C 2011 Weissenstein et al; licensee BioMed Central Ltd. This is an Open Access article distributed under the terms of the Creative Commons Attribution License (http://creativecommons.org/licenses/by/2.0), which permits unrestricted use, distribution, and reproduction in any medium, provided the original work is properly cited. care expected from the patient and the perceived quality of medical treatment. The special aspect of the concept of patient satisfaction is that quality standards are not evaluated any more by teams of experts but by the patients themselves [2].

A very useful tool for the assessment of parent satisfaction is a questionnaire-based survey. The advantages of a questionnaire are manifold: The parents can answer questions anonymously and don't have to fear negative consequences because of their judgment. Questionnaires are, in contrast to interviews, more economic, faster and are regarded as more voluntary from the parents [3-5].

But why is parental satisfaction with a pediatric practice so important? 
There are mainly 5 reasons:

1. Parental satisfaction can be used as an indicator of quality care

2 . For the best possible medical treatment of children it is indispensable that the doctor includes the parents in the treatment regime

3. Compliance with medical regimen

4. Understanding of medical information

5. In times of the free market economy the new critical patient has a free choice of pediatric day centers

Some authors claim that the parents are not in the state of mind to properly assess every aspect of a pediatric practice since they have their sick children to worry about. However, parents are supposed to be rational and capable of making intelligent choices with respect to their children's health, and if they are capable of this, should they not also be capable of questioning and assessing the activities of the staff as well as the physician?

There is evidence that satisfaction with pediatric medical visits is related to parents' compliance with medical regimes, understanding and retention of medical information, and continuity of care [6-10]. However, there are only few multiitem measures of parent satisfaction with the pediatric practice. That is why the members of the "Ped Mind Institute", an institution which concentrates on clinical research in the field of pediatrics, have developed a parental satisfaction questionnaire. The empirical detectable benefit of such a survey is expressed by the number of identified problems, and the interest, as well as the acceptance of the medical staff in the results of the questioning. Our aim is the identification of factors that lead to a high level of parental satisfaction as well as to the stabilization and improvement of the parents' trust in the pediatric practice.

\section{Patients and Methods}

Between October and November 2010, 127 parents of children who were treated at the pediatric practice in Epe (Germany) were asked to fill out the parental satisfaction questionnaire and 67 responded. After the parents had seen the doctor they were asked for 10 to 15 minutes of their time to fill out the questionnaire anonymously. By asking the parents directly on site a high participation was anticipated.

\section{The parental satisfaction questionnaire}

At the beginning, 27 items were generated. The items were constructed on the basis of several sources, including the "Sleep Laboratory for Children Survey, Dresden" [11], studies of parental satisfaction with pediatric medical encounters $[7,12]$ and interviews with parents of pediatric patients. The items were divided into 3 scales. The scales were as follows: "satisfaction concerning the infrastructure and organization" (13 items), "satisfaction concerning the communicative and empathic competence of the doctor as well as the other staff" (9 items) and finally the "result and the overall impression"(5 items). After each scale the parents had the opportunity to write a comment.

In addition 4 questions were asked for those children who are old enough so that their interaction with the doctor could be assessed by their parents. In one of these questions the children themselves were asked to mark their general impression of the pediatric practice on a smiley scale [13]. Furthermore the questionnaire contains 12 questions regarding sociodemographic information of parents and their children as well as situative conditions. The personal questions were put at the end of the questionnaire with the intention of allowing the parents to adjust and feel secure about the anonymity of the survey.

All items employed a four-point Likert scale. An even number of 4 points was used as respondents may avoid using extreme response categories (central tendency bias). The 4 point scale (very satisfied- satisfied- unsatisfiedvery unsatisfied) was coded with the numbers 4 to 1 so that the highest number correlates with the highest degree of agreement. Of these items 6 were negatively worded to reduce potential impact of an acquiescence response bias [14]. A pretest was performed by handing the questionnaire to 32 parents who were told to fill out the questionnaire and mark anything that is not clear. Afterwards they were asked if everything was understandable and if they had any other comments. Cronbachs Alpha was 0,805 which is a relatively good value considering it has to be at least over 0,7. Also all means where settled between 3 and 4 , which is already a good indicator for the satisfaction of the parents with the pediatric practice.

\section{Analysis of the questionnaire}

All calculations were performed with the statistic program SPSS, version 16.0. Beside the descriptive presentation of the results we compared the means of the parental satisfaction to the specific characteristics of the parents by using the t-test. Furthermore our questionnaire was analyzed regarding situative and sociodemographic different characteristics by using the scores of the 3 scales.

\section{Results \\ Returns}

From 127 parents, 67, (52,7\%) agreed to fill out the questionnaire. A detailed description of the sample of parents who participated in the survey is listed in Table 1.

\section{Satisfaction with infrastructure and organization}

The results concerning the infrastructure and organization of the pediatric day center can be seen in Table 2 . 
Table 1 Description of sample of parents

\begin{tabular}{|c|c|c|}
\hline Description of sample & $\mathbf{n}$ & $\%$ \\
\hline \multicolumn{3}{|l|}{ Form filler of questionnaire } \\
\hline mother & 57 & 93,4 \\
\hline father & 4 & 6,6 \\
\hline \multicolumn{3}{|l|}{ Age of parents } \\
\hline under 20 years & 0 & 0 \\
\hline $21-30$ years & 24 & 38,7 \\
\hline $31-40$ years & 29 & 46,8 \\
\hline over 40 years & 9 & 14,5 \\
\hline \multicolumn{3}{|l|}{ graduation degree of parents } \\
\hline secondary modern school & 4 & 7,0 \\
\hline middle school & 34 & 59,6 \\
\hline graduation from high school & 19 & 33,4 \\
\hline \multicolumn{3}{|l|}{ Parents with child at the age of } \\
\hline $1-5$ & 44 & 70,9 \\
\hline $5-10$ & 10 & 16,2 \\
\hline $10-15$ & 8 & 12,9 \\
\hline \multicolumn{3}{|l|}{ Gender of child } \\
\hline male & 33 & 52,4 \\
\hline female & 30 & 47,6 \\
\hline \multicolumn{3}{|l|}{ Parents with indication for child } \\
\hline screening & 15 & 25,4 \\
\hline vaccination & 10 & 16,9 \\
\hline acute illness (flu, stomach ache,...) & 28 & 47,5 \\
\hline chronic illness (obstipation, urinary infection) & 4 & 6,8 \\
\hline controls (after operations) & 2 & 3,4 \\
\hline \multicolumn{3}{|l|}{ Which child is presented in the practice } \\
\hline first child & 30 & 47,6 \\
\hline second child & 22 & 34,9 \\
\hline third or further child & 11 & 17,5 \\
\hline \multicolumn{3}{|c|}{ Number of times the parents visited the pediatric practice } \\
\hline never & 1 & 1,6 \\
\hline once & 1 & 1,6 \\
\hline often & 59 & 96,8 \\
\hline \multicolumn{3}{|l|}{ Insurance status of child } \\
\hline statuory health insurance & 57 & 90,4 \\
\hline statutory health insurance \& private insurance & 3 & 4,8 \\
\hline private health insurance & 3 & 4,8 \\
\hline \multicolumn{3}{|l|}{ Parents with child after visit } \\
\hline with therapy & 37 & 74,0 \\
\hline without therapy & 13 & 26,0 \\
\hline
\end{tabular}

\section{Analysis}

The outcome of the general impression of the parents depends on many factors. It starts at the very beginning of their visit to the pediatric day center. Significant levels were reached by the questions concerning the atmosphere and décor of the waiting area, the duration of the consultation hours and the waiting time.

If the parents are "satisfied" with the waiting area, their general impressions are rated higher (mean 3,47) and even significantly $(\mathrm{p}=0,036)$ more higher if they are "very satisfied" (mean 3,76) with the waiting area. Parents who were "very satisfied" with the consulting hours were also more satisfied (mean 3,71) with the practice in general, than parents who were only "satisfied" (mean 3,30). These values reached a significant level in a t-test $(\mathrm{p}=0,03)$.

The overall waiting time was 13,74 minutes and although this is a good value, the mean satisfaction was only 3,6. Three parents came without an appointment, but they did not have to wait longer than others, in fact their mean waiting time was only 6 minutes. We also detected a strong correlation between the length of the waiting time and the satisfaction of the waiting time. The satisfaction of the waiting time of parents who waited up to 10 minutes was 3,86 while the mean satisfaction of parents who waited more than 10 minutes was 3,32 . These values are very significant in a t-test ( $p$ $=0,004)$. Furthermore we discovered that parents who were "satisfied" with the waiting time were also mostly "satisfied" with the practice. These values reached a significant value in a t-test $(\mathrm{p}=0,02)$.

\section{Expertise of staff and doctor}

The results concerning the expertise, communication skills and empathy of the medical staff as well as the doctor can be seen in Table 3 .

\section{Analysis}

The expertise of the staff and the doctor and their ability to respond to the parents play an important role in the overall satisfaction of the parents. For the parents the most important factor for their satisfaction was that the doctor had enough time for them. This reached the highest level of satisfaction, namely a mean of 3,94. This value was highly significant $(\mathrm{p}=<0,001)$ in a t-test. The parents who were "unsatisfied" by the way their questions and wishes were taken into consideration by the medical staff, rated their general impression of the practice worse (mean 2,5) than parents who were "satisfied" (mean 3,5). The parents who were "very satisfied" by the way they were treated by the staff rated their overall impression of the practice even higher (mean 3,72) which is highly significant ( $p=0,001$ ).

It was also very important, that the doctor listened carefully to what they had to say. If they were "unsatisfied" by the way the doctor had listened to them they only reached a mean overall satisfaction of 2,50 . In the case that the parents were "satisfied", they reached a 
Table 2 Results concerning infrastructure and organization

\begin{tabular}{|c|c|c|c|c|}
\hline \multirow[b]{2}{*}{ QUESTION } & \multicolumn{4}{|c|}{ EVALUATION } \\
\hline & $\begin{array}{c}\text { very } \\
\text { satisfied- }\end{array}$ & satisfied- & unsatisfied- & $\begin{array}{l}\text { very } \\
\text { unsatisfied }\end{array}$ \\
\hline 1. Satisfaction with the telephonic availability of the pediatric practice & $76.1 \%$ & $22.4 \%$ & $1.5 \%$ & $0 \%$ \\
\hline 2. Friendliness of the staff at the reception & $91 \%$ & $7.5 \%$ & $0 \%$ & $1,5 \%$ \\
\hline 3 a-d. Questions concerning the consulting hours (duration, waiting period, ...) & $79 \%$ & $17 \%$ & $3 \%$ & $1 \%$ \\
\hline $\begin{array}{l}4 \text { a-d. Questions concerning infrastructure of the practice (parking possibilities, waiting } \\
\text { area,...) }\end{array}$ & $55 \%$ & $29 \%$ & $13 \%$ & $3 \%$ \\
\hline 5. Satisfaction with waiting time & $66 \%$ & $28 \%$ & $6 \%$ & $0 \%$ \\
\hline
\end{tabular}

significantly $(\mathrm{p}=0,007)$ higher level of general satisfaction (mean 3,23) and even very significantly higher $(\mathrm{p}=$ $<0,001$ ) was their general satisfaction (mean 3,88) when they were "very satisfied" with the doctors listening abilities. Furthermore a significant positive correlation between the parents estimations, whether they felt understood by the doctor, have understood the suggested therapy and their general satisfaction could be found.

\section{Achieved Results}

The achieved results also play an important role for the parental satisfaction. Forty-two parents $(70,0 \%)$ were "very satisfied" with the achieved results and $66,1 \%$ were "very satisfied" with the suggested therapy. 84,2\% would definitely recommend the practice to others. Finally the parents were asked what their overall impression of the pediatric practice is and two thirds $(68,3 \%)$ were very satisfied as can be seen in Figure 1: Overall satisfaction of parents of pediatric practice. In the last question of this part the children who were old enough were asked about their overall impression and 24 children had answered. $83,3 \%$ of them "very satisfied" and 16,7\% were "satisfied".

Parents who are satisfied with their visit are very likely to come back again. The means of overall satisfaction was 3,86 which is a very high score (max. 4) and therefore $91,5 \%$ of the parents would come again with their children. We found a highly significant $(\mathrm{p}=0,004)$ relation between the suggested therapy of the doctor and their general satisfaction. When the parents were "satisfied" with the suggested therapy they only reached a mean general satisfaction of 3,31 , but when they were "very satisfied" they reached a mean satisfaction level of 3,81 .

We detected no significant relation between the demographic variables tested and satisfaction, except for parents who had a statutory health insurance for their child, who were more satisfied (mean satisfaction 3,7) than parents who had a private insurance for their child (mean satisfaction 3,0). The values reached significance level in a t-test $(\mathrm{p}=0,048)$.

\section{Discussion}

Vuori stated 1987 that: "Patient satisfaction is an attribute of quality per se: without patient satisfaction there cannot be good care" [15]. That is the reason why it is very important, apart from a good professional medical care, that parents of children visiting a pediatric practice are satisfied in general. There are many factors that determine whether the parents are satisfied after their visit to the pediatric day center. Not only is the doctors' ability to communicate adequately, listen carefully or spend sufficient time with the parents essential for a high satisfaction, but also other factors as décor of the waiting area, adequate consultation hours and a short waiting period.

The response rate for mailed questionnaires usually lies at $10-20 \%$ [4] and by distributing the questionnaires out personally by the doctor we aimed at influencing the returns rate positively [16]. At least 50 questionnaires should be distributed in order to obtain a representative result [16] and Babbie (1990) stated that a returns rate of at least $50 \%$ is adequate for analysis and reporting while a response rate of $60 \%$ is good [17]. Therefore our response rate of $52,7 \%$ can be valued as

Table 3 Results concerning expertise of medical staff and doctor

\begin{tabular}{|c|c|c|c|c|}
\hline \multirow[b]{2}{*}{ QUESTION } & \multicolumn{4}{|c|}{ EVALUATION } \\
\hline & very satisfied- & satisfied- & unsatisfied- & very unsatisfied \\
\hline $1 \mathrm{a}-\mathrm{b}$. Friendliness and helpfulness of medical staff & $89 \%$ & $9 \%$ & $2 \%$ & $0 \%$ \\
\hline 2 a-g. Expertise, empathy and communication of the doctor & $61 \%$ & $28 \%$ & $8 \%$ & $3 \%$ \\
\hline $2 \mathrm{~h}$-j. Interaction of the doctor with the child & $64 \%$ & $24 \%$ & $7 \%$ & $5 \%$ \\
\hline
\end{tabular}




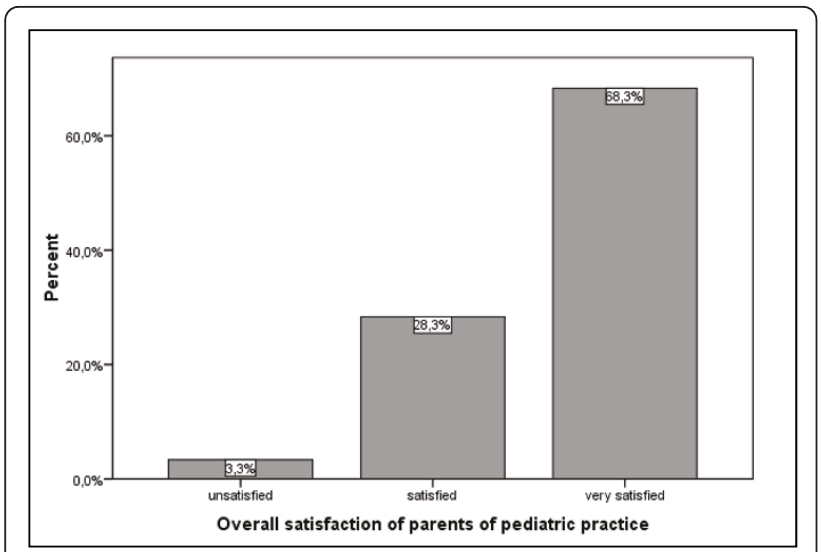

Figure 1 Overall satisfaction of parents of pediatric practice.

adequate. The time of the distribution of the questionnaires is of special importance. The problem with the questioning at the beginning of the visits is that the parents are not able to asses every aspect properly. When handing the questionnaire at the end of the visit it is well-known that the patients have the tendency to judge the practice more favorably (Halo-Effect: the positive experience of the end of the visit retrospectively embellishes the personal recollections)[18], however, it seemed to be the best method. To fully understand the context of our survey, a good knowledge of the German health system, especially for children, is advantageous. In Germany every child is insured either automatically in a family statuory health insurance or in a private insurance. In the case of an illness the first point of contact is the pediatrician, who can decide to transfer the children to a specialist if necessary. All costs are paid by their insurance.

Parent satisfaction with the pediatric day center visit is significantly negatively related to wait times [19]. The mean waiting period was 13,74 minutes, which is a very good value in contrast to the average calculated waiting time of 28 minutes for pediatric day centers [20,21] and therefore we would have expected an even higher rate of satisfaction. A possible explanation could be that the majority of parents $(84 \%)$ tend to overestimate their waiting time [22] and therefore, a high percepted waiting time is a negative correlation to overall satisfaction [23].

Even more important, and leading to higher levels of satisfaction, is the relationship between the parents and their doctor. We discovered that the highest rate of general satisfaction was achieved, when the parents were "very satisfied" with the time their doctor had given them. This confirms the findings of other authors. Feddock et al. (2010) and Anderson et al. (2007) both discovered that time with the physician was positively related to satisfaction. Furthermore, it even moderated any observed effect of long wait time $[19,21]$. In a further study Feddock states, that physicians can even mediate the negative effects of long waiting times by spending more time with their patients [24]. For the parents as well as for patients, it is very important that the doctor listens carefully, that they feel understood and furthermore, that they understand the proposed therapy $[12,25]$. For the doctor on the other hand, a satisfied parent is very important, since there is a significant relation between patients, or, in our case parents', satisfaction and compliance [26]. Then again, a good compliance is essential for a successful treatment $[27,28]$. We further discovered that, for the parents, the doctor-child relation does not seem very important. Since in a pediatric day center the children are mostly very young, the parents take the role of the primary contact and therefore a good relationship must be built primarily with them.

We discovered that "very satisfied" patients are extremely likely to visit the practice again and all of them would recommend the practice to others. During free market economy times, were the new critical patient or parent has a free choice of pediatric day centers this is of special importance. Other authors also state that satisfied patients will visit the practice again [29]. Furthermore, a satisfied patient will recommend the practice in average on 4 to 5 people [30]. This may not seem much, but 100 satisfied patients will bring the practice 400 to 500 potential new patients.

Finally, we detected no significant relation between the demographic variables tested and satisfaction, except for between the parents who had a statuory health insurance for their child and those, who had a private health insurance. We found that the parents who had a private health insurance for their child were less satisfied in general. One reason could be that they had higher expectations and demands that were not fulfilled. On the other hand, only 3 parents had a private insurance for their child and therefore, the results are more likely not representative. While some authors claim that there is a strong relation between sociodemographic characteristics, such as age, sex, educational background and satisfaction $[28,31]$, other recent findings state that there is a large inconsistency [32]. Francis et al. found no differences in demographic variables and satisfaction [26], Hall and Dornan state in their review that reviewers have failed to reach confident conclusions [33], and Fox and Storms [34] even summarized the situation as follows: "The literature on satisfaction with health care presents contradictory findings about sociodemographic variables... The situation has grown so chaotic that some writers dismiss [sociodemographic] variables as reliable predictors of satisfaction [p. 557]." 
These results also confirm our findings, of a non-existent relation between sociodemographic variables and parental satisfaction.

There is the argument that patient satisfaction cannot be measured in a way that would generate useful results to improve the quality of care. It is difficult to define what quality means for the parents. There is a large intra-individual variation in what is considered to be qualitatively important and sometimes it can be even ethically unacceptable for the physician of a pediatric practice to satisfy parents' wishes, for example those concerning treatment regimes or other measures [15]. Our aim was to assess, which factors in a pediatric day center lead to a high parental satisfaction level. We have ruled out sociodemographic variables linked to a high satisfaction and found that the ability of the doctor to interact with the parents is the main predictor for a high level of satisfaction. However, also other factors, such as short waiting period, a friendly staff and a nicely decorated waiting area are essential for the smooth running of a practice and as they are rather implied by parents, they turn out negative if not available. We have also received negative news. It was often mentioned that there were not enough toys in the waiting area, for example. As a result we have bought more supplies so that the children have more distractions. We have also found out that the parents were rather unsatisfied when the doctor did not pay attention to their child or did not have enough time in general. The doctor has received a copy of this analysis, and will take these points into account in the future.

\section{Authors' contributions}

All authors contributed equally and approved the manuscript

\section{Competing interests}

The authors declare that they have no competing interests.

Received: 18 April 2011 Accepted: 5 July 2011 Published: 5 July 2011

\section{References}

1. U.S. National Center for Health Services Research and Development: Computer simulation model for evaluation of the health care delivery system. Washington DC: US Government Printing Office; 1973.

2. Bayer M, Jaeck T: Qualitätsmanagement im Krankenhaus -Organisationsbindung von Mitarbeitern und Zufriedenheit von Patienten. Der Hallesche Graureiher 2006, 5.

3. Williams B: Patient satisfaction: a valid concept? Soc Sci Med 1994, 38:509-516.

4. Bailey KD: Methods of social research Simon and Schuster; 1994

5. Wood MJ, Kerr JC: Basic Steps in Planning Nursing Research: From Question to Proposal. Jones and Bartlett 2001.

6. Becker $\mathrm{MH}$, Drachman $\mathrm{RH}$, Kirscht JP: Predicting mothers' compliance with pediatric medical regimens. J Pediatr 1972, 81:843-854.

7. Francis V, Korsch BM, Morris MJ: Gaps in doctor-patient communication. Patients' response to medical advice. N Engl J Med 1969, 535-540.

8. Gray PG, Cartwright A: Choosing and changing doctors. Lancet 1953, 265:1308-1309.
9. Bertakis $\mathrm{KD}$ : The communication of information from physician to patient: a method for increasing patient retention and satisfaction. $J$ Fam Pract 1977, 5:217-222.

10. Linn LS: Factors associated with patient evaluation of health care. Milbank Mem Fund Q Health Soc 1975, 53:531-548.

11. Abdel-Haq A, Paditz E, Schuetze P, Kugler J, Koch R: Internal Quality Assurance in the Children's Sleep Laboratory - Surveying Parental Satisfaction with the 'Sleep Laboratory for Children Survey, Dresden' and Subsequent Optimization. Somnnologie 2005, 9:33-51.

12. Korsch BM, Gozzi EK, Francis V: Gaps in doctor-patient communication. 1. Doctor-patient interaction and patient satisfaction. Pediatrics 1968, 42:855-871.

13. Jaeger R: Construction of a rating scale with smilies as symbolic labels. Diagnostica 2004, 50:31-38.

14. Winkler JD, Kamouse DE, Ware JE: Controlling for acquiescence response set in scale development. J Appl Psychol 1982, 67:555.

15. Vuori $\mathrm{H}$ : Patient satisfaction-an attribute or indicator of the quality of care? Qual Rev Bull 1987, 13:106-108.

16. Dierks ML, Bitzer EM, Wilhelm Schwartz FM: Patientenbefragungen in der Arztpraxis. Zeitschrift für ärztliche Fortbildung und Qualitätssicherung 2000, 94:389-395.

17. Babbie ER: Survey research methods Wadsworth Pub. Co.; 1990

18. Nisbett RE, Timothy DW: The halo effect: Evidence for unconscious alteration of judgments. Journal of Personality and Social Psychology 1977, 35:250-256.

19. Feddock CA, Bailey PD, Griffith CH, Lineberry MJ, Wilson JF: Is time spent with the physician associated with parent dissatisfaction due to long waiting times? Eval Health Prof 33:216-225.

20. Geringste Wartezeit beim Zahnarzt. [http://www.agz-rnk.de/agz/content/2/ aktuelles/akt_00584.php], retrieved: 02.02.2011.

21. Anderson RT, Camacho FT, Balkrishnan R: Willing to wait?: the influence of patient wait time on satisfaction with primary care. BMC Health Serv Res 2007, 7:31.

22. Waseem M, Ravi L, Radeos M, Ganti S: Parental perception of waiting time and its influence on parental satisfaction in an urban pediatric emergency department: are parents accurate in determining waiting time? South Med J 2003, 96:880-883.

23. Thompson DA, Yarnold PR, Williams DR, Adams SL: Effects of actual waiting time, perceived waiting time, information delivery, and expressive quality on patient satisfaction in the emergency department. Ann Emerg Med 1996, 28:657-665.

24. Feddock CA, Hoellein AR, Griffith CH, Wilson JF, Bowerman JL, Becker NS, Caudill TS: Can physicians improve patient satisfaction with long waiting times? Eval Health Prof 2005, 28:40-52.

25. Robb M, Barrett S: Communication, relationships and care: a reader. Routledge 2003.

26. Francis V, Korsch BM, Morris MJ: Gaps in doctor-patient communication. Patients' response to medical advice. N Engl J Med 1969, 280:535-540.

27. Ley P: Satisfaction, compliance and communication. Br J Clin Psychol 1982, 21(Pt 4):241-254

28. Pascoe GC: Patient satisfaction in primary health care: a literature review and analysis. Eval Program Plann 1983, 6:185-210.

29. Streit V, Letter M: Marketing fuer Arztpraxen Springer; 2004.

30. Thill KD: Patientenzufriedenheit in der Arztpraxis: Die Voraussetzung für eine erfolgreiche unternehmerische Praxisführung. Deutscher Aerzteverlag 2008.

31. Locker D, Dunt D: Theoretical and methodological issues in sociological studies of consumer satisfaction with medical care. Soc Sci Med 1978, 12:283-292.

32. Weiss GL: Patient satisfaction with primary medical care. Evaluation of sociodemographic and predispositional factors. Med Care 1988, 26:383-392.

33. Hall JA, Dornan MC: Patient sociodemographic characteristics as predictors of satisfaction with medical care: a meta-analysis. Soc Sci Med 1990, 30:811-818.

34. Fox JG, Storms DM: A different approach to sociodemographic predictors of satisfaction with health care. Soc Sci Med A 1981, 15:557-564.

doi:10.1186/1824-7288-37-31

Cite this article as: Weissenstein et al:: Parent satisfaction with a pediatric practice in Germany: A questionnaire-based study. Italian Journal of Pediatrics 2011 37:31. 